Article

\title{
Synthesis and Study of Gas Transport Properties of Polymers Based on Macroinitiators and 2,4-Toluene Diisocyanate
}

\author{
Ilsiya M. Davletbaeva ${ }^{1}$, Ilnaz I. Zaripov ${ }^{2, *}$, Alexander I. Mazilnikov ${ }^{1}$, Ruslan S. Davletbaev ${ }^{2}$, \\ Raphael R. Sharifullin ${ }^{3}$, Artem A. Atlaskin ${ }^{4}$, Tatyana S. Sazanova ${ }^{4}$ and Ilya V. Vorotyntsev ${ }^{4}$ (D) \\ 1 Department of Synthetic Rubber, Kazan National Research Technological University, 68 K. Marx str., \\ 420015 Kazan, Russia; davletbaeva09@mail.ru (I.M.D.); mazillove001@gmail.com (A.I.M.) \\ 2 Department for Materials Science, Welding and Industrial Safety, Kazan National Research Technical \\ University, n.a. A.N. Tupolev, 10 K. Marx str., 420111 Kazan, Russia; darus@rambler.ru \\ 3 Laboratory of Scientific and Research Center, PJSC Nizhnekamskneftekhim, 23 Sobolekovskaya str., \\ 423574 Nizhnekamsk, Russia; rafael_sharif@mail.ru \\ 4 Laboratory of Membrane and Catalytic Processes, Nizhny Novgorod State Technical University n.a. R.E. \\ Alekseev, 24 Minin str., 603950 Nizhny Novgorod, Russia; atlaskin@gmail.com (A.A.A.); \\ yarymova.tatyana@yandex.ru (T.S.S.); ilyavorotyntsev@gmail.com (I.V.V.) \\ * Correspondence: zaripovilnaz@gmail.com; Tel.: +7-906-328-0747
}

Received: 24 February 2019; Accepted: 17 March 2019; Published: 20 March 2019

check for updates

\begin{abstract}
Nowadays, block copolymers hold great promise for the design of novel membranes to be applied for the membrane gas separation. In this regard, microporous block copolymers based on a macroinitiator with an anionic nature, such as potassium-substituted block copolymers of propylene oxide and ethylene oxide (PPEG) and 2,4-toluene diisocyanate (TDI), were obtained and investigated as effective gas separation membranes. The key element of the macromolecular structure that determines the supramolecular organization of the studied polymers is the coplanar blocks of polyisocyanates with an acetal nature (O-polyisocyanate). In the present research, the influence of the content of peripheral polyoxyethylene (POE) blocks in PPEG on the supramolecular structure processes and gas transport characteristics of the obtained polymers based on PPEG and TDI was investigated. According to the study of polymers if the POE block content is $15 \mathrm{wt} \%$, the polyoxypropylene segments are located in the internal cavity of voids formed by O-polyisocyanate blocks. When the POE block content is $30 \mathrm{wt} \%$, the flexible chain component forms its own microphase outside the segregation zone of the rigid O-polyisocyanate blocks. The permeability for polar molecules, such as ammonia or hydrogen sulfide, significantly exceeds the permeability values obtained for non-polar molecules $\mathrm{He}, \mathrm{N}_{2}$ and $\mathrm{CH}_{4}$. A relatively high permeability is also observed for carbon dioxide. At the same time, the content of POE blocks has a small effect on the permeability for all studied gases. The diffusion coefficient increases with an increase in the POE block content in PPEG for all studied gases.
\end{abstract}

Keywords: macroinitiator; 2,4-toluene diisocyanate; microporous block copolymers; gas transport; membrane; gas separation

\section{Introduction}

Due to the constantly growing requirements for the characteristics of substances, such as quality (purity) and environmental friendliness, the design and development of energy-efficient methods and purification technologies have become increasingly popular [1-4]. In the field of chemical engineering of gas purification, the membrane-based separation technique may be considered as an attractive 
alternative to conventional energy-intensive processes, such as sorption, crystallization, distillation etc. The ideal membrane process would allow for high selective separation due to the physicochemical features of the material [5-7], which passes one component of the gas mixture and rejects others in a continuous steady-state regime. Moreover, the membrane-based process provides separation without any phase transition, does not require heat supply or removal at ambient temperatures. Furthermore, apparatuses should be characterized by simple hardware design. Thus, the high purification of gases is a potential separation field in which membrane technology can be successfully applied individually and as part of hybrid processes [8-11].

Block copolymers can potentially be used to obtain new membrane materials that can be applied for the selective separation of gases. Poly(styrene-butadiene-styrene) block copolymers were the most studied in this series [12-15]. According to these works, the degree of the microphase separation of rigid and flexible blocks and the particularity of the supramolecular organization of macrochains significantly affect the gas transport characteristics.

At the same time, the gas selectivity can be improved by adding a third segment to diblock copolymers [16,17]. The properties of the triblock copolymer, poly(styrene-ethylene oxide-styrene) and its mixtures with polyethylene glycol as a membrane for the release of $\mathrm{CO}_{2}$ were studied in $[18,19]$. The selectivity of such membranes to $\mathrm{CO}_{2}$ is due to the unusually high affinity of $\mathrm{CO}_{2}$ for PEG. By changing the morphology of triblock copolymers containing PEG and the affinity between the copolymer, the selectivity to $\mathrm{CO}_{2}$ /gas vapors was significantly improved. In reference [20], the comparison of existing membranes based on the block and random polymers of PEG was performed. It turned out that when the PEG content increases, the permeability of membranes decreases but selectivity increases. At the same time, the membranes based on random polymers showed the best selectivity with a PEG content of $20 \%\left(\mathrm{CO}_{2} / \mathrm{CH}_{4}=37.31\right.$ and $\left.\mathrm{H}_{2} / \mathrm{CH}_{4}=33.44\right)$.

The interesting results related to the relationship between the structure and gas transport characteristics of polyurethane (PU) films obtained on the basis of polyethers and polyesters are presented in references [21-28]. Gas permeability through polyurethane-based membranes can be controlled by changing the ratio of rigid and flexible segments [29,30]. When the content of rigid segments increases, the gas permeability of PU decreases due to a decrease in free volume, segmental mobility and consequently, diffusion [31-37]. On the contrary, an increase in the content of flexible segments in PU leads to the efficiency of microphase separation and an increase in their gas permeability [38,39]. Moreover, it was revealed that the nature of flexible segments was responsible for the efficiency of gas transportation through membranes [40-45]. There is high selectivity for polyurethane membranes obtained from polyethylene glycol but there is low gas permeability for $\mathrm{CO}_{2}$. Thus, when the permeability for carbon dioxide is 150 Barrer, the selectivity of $\mathrm{CO}_{2} / \mathrm{N}_{2}$ mixture can reach 50, which is comparable to the separation efficiency of commercial Polyactive $[43,44]$ and Pebax 1657 membranes $[20,44]$. Nonetheless, the practical use of polyurethane-based membranes is limited by weak thermomechanical stability and their low resistance to plasticization during gas separation. It was found that the branching created in their topological macromolecular structure can have a significant impact on the gas transport properties of polyurethanes. In such a way, the polyurethanes derived from hyperbranched amino ethers of boric acid can show high permeability in combination with high selectivity during the separation of gas mixtures containing ammonia [6,8].

Thus, a change in the nature and ratio of flexible and rigid blocks leads to a change in the properties of the polymer, including those related to gas transport. The use of PEG as a hydrophilic flexible chain component is an important element of the impact on the gas transport characteristics of membrane materials based on block copolymers.

Apart from the gas transport properties of polymeric membranes for the separation of gas mixtures containing methane, nitrogen, carbon dioxide, hydrogen and helium, which have been widely investigated, the processes of the purification of polar and aggressive gases, including ammonia and hydrogen, has not been broadly presented in the literature. 
Previous works [45-48] have described microporous polymers and determined that the specific characteristics of the supramolecular structure of the former are due to the polyisocyanate blocks of acetal nature (O-polyisocyanates) as a rigid chain component. Figure 1 shows the scheme for obtaining such polymers. This scheme is based on the polyaddition reaction of 2,4-toluene diisocyanate (TDI) activated by the macroinitiator (MI), which is basically a potassium-substituted block copolymer of propylene and ethylene oxide (PPEG).

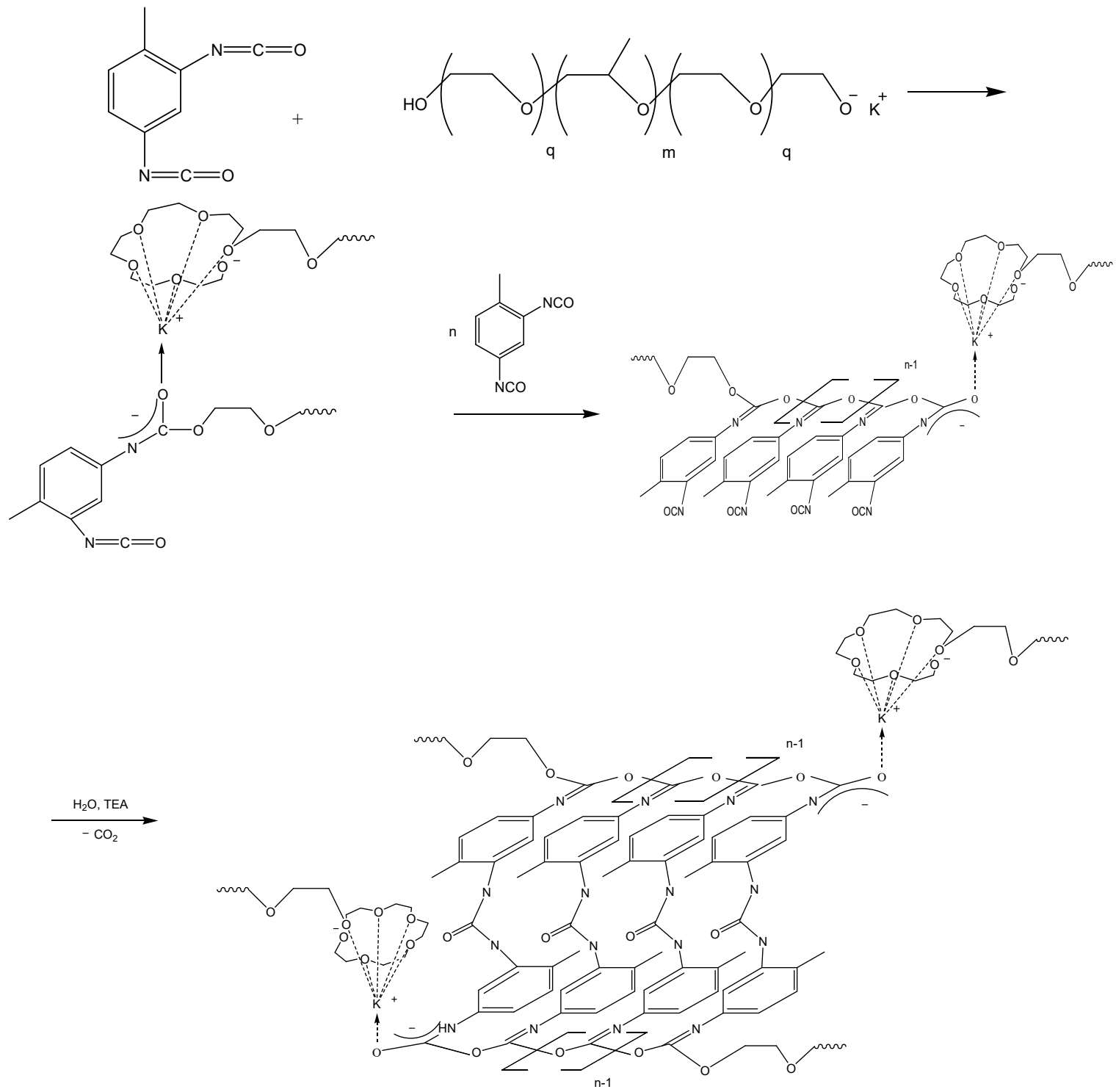

Figure 1. Scheme of O-polyisocyanate blocks formation.

The flexible chain component in these polymers is a block copolymer of propylene and ethylene oxides. Considering that polyoxyethylene (POE) and polyoxypropylene blocks play an important role in gas separation processes, the purpose of this study is to research the influence of the peripheral POE block content in PPEG on supramolecular structure processes, morphology, chemical structure of the inner surface of micropores and gas transport characteristics of polymers obtained on the basis of PPEG and TDI for gases, including polar and aggressive gases (ammonia and hydrogen sulfide). 


\section{Materials and Methods}

\subsection{Materials}

The block copolymer of propylene oxide with ethylene oxide (PPEG) with the formula of $\mathrm{HO}\left[\mathrm{CH}_{2} \mathrm{CH}_{2} \mathrm{O}\right]_{n}\left[\mathrm{CH}_{2}\left(\mathrm{CH}_{3}\right) \mathrm{CH}_{2} \mathrm{O}\right]_{\mathrm{m}}\left[\mathrm{CH}_{2} \mathrm{CH}_{2} \mathrm{O}\right]_{n} \mathrm{~K}$ and molecular weight of $4200 \mathrm{~g} / \mathrm{mol}$, containing 15, 20, 30 and $40 \mathrm{wt} \%$ of peripheral POE blocks, were synthesized in the laboratory of Scientific and Research Center, PJSC Nizhnekamskneftekhim (Nizhnekamsk, Russia), which also had a content of potassium alcholate groups that was $10.9 \%$ of the total number of functional groups. The 2,4-toluene diisocyanate 98\% (TDI) was purchased from Sigma-Aldrich (St. Louis, MO, USA). PPEG was additionally dried at a reduced pressure and at an elevated temperature of $353 \mathrm{~K}$ to reduce the moisture concentration to $0.01 \%$.

In the gas separation investigation of the prepared polymer gases (methane, hydrogen sulfide, carbon dioxide, helium and nitrogen), all gases used had a purity of no less than 99.995\% (NII KM, Nizhny Novgorod, Russia). High purity ammonia (99.99999\%; Firm HORST Ltd., Moscow, Russia) was employed for permeability studies.

\subsection{Synthesis of Polymers Based on TDI and PPEG}

The reaction was carried out in toluene at $20{ }^{\circ} \mathrm{C}$ in a flask equipped with a reflux condenser. The polymerization process proceeded with the constant stirring using a magnetic stirrer. The flask contained PPEG ( $1 \mathrm{~g})$, toluene $(7.9 \mathrm{~g})$, bisphenol A $(0.004 \mathrm{~g})$ and acetic acid $(0.007 \mathrm{~g})$. The reaction mass was mixed at a given temperature until the complete dissolution of PPEG took place. After this, TDI $(0.62 \mathrm{~g})$ at a molar ratio of [PPEG]:[TDI] = 1:15 was introduced. Five minutes after being mixing with TDI, the reaction system was loaded with triethylamine $(0.0072 \mathrm{~g})$ and water $(0.001 \mathrm{~g})$. Ten minutes after the reaction mass was dispensed to Petri dish, it was cured at room temperature for $72 \mathrm{~h}$.

\subsection{Polymer Characterization}

\subsubsection{Tensile Stress-Strain Measurements}

Tensile stress-strain measurements were obtained from the film samples with dimensions of $40 \mathrm{~mm} \times 15 \mathrm{~mm}$ using Universal Testing Machine Inspekt mini (Hegewald \& Peschke Meß- und Prüftechnik GmbH, Nossen, Germany) at $293 \pm 2 \mathrm{~K}$ and $1 \mathrm{kN}$. The crosshead speed was set at $50 \mathrm{~mm} / \mathrm{min}$ and the test continued until sample failure. A minimum of five tests was analyzed for each sample and the average values were reported.

\subsubsection{Fourier Transform Infrared (FTIR) Spectroscopy Analysis}

The FTIR spectra were recorded on an InfraLUM FT 08 Fourier transform spectrometer (Lumex, St. Petersburg, Russia) using the attenuated total reflection technique in the spectral range of $3800-400 \mathrm{~cm}^{-1}$. The spectral resolution was $2 \mathrm{~cm}^{-1}$ and the number of scans was 10 .

\subsubsection{Thermomechanical Analysis}

The thermomechanical curves of polymer samples were obtained using TMA 402 F (Netzsch, Selb, Germany) thermomechanical analyzer in the compression mode. The thickness of the sample was $2 \mathrm{~mm}$, the rate of heating was $3 \mathrm{~K} / \mathrm{min}$ from room temperature to $540 \mathrm{~K}$ in the static mode and the load was $2 \mathrm{~N}$.

\subsubsection{Thermal Gravimetric Analysis}

Thermal gravimetric analysis (TGA) was performed using STA-600 TGA-DTA combined thermal analyzer (Perkin Elmer, Waltham, MA, USA). The samples (0.1 g) were loaded in alumina pans and heated from 297 to $870 \mathrm{~K}$ at a rate of $5 \mathrm{~K} / \mathrm{min}$ in a nitrogen atmosphere. 


\subsubsection{Atomic Force Microscopy Topology Analysis}

The atomic force microscopy (AFM) was used to reveal the surface morphology of samples. All AFM measurements were obtained using an atomic force microscope (SPM-9700, Shimadzu, Kyoto, Japan) and silicon vibration cantilevers (POINTPROBE FMR-20, Neuchaatel, Switzerland) with a typical tip curvature radius of no greater than $8 \mathrm{~nm}$. The lateral scan area was of up to $5 \mu \mathrm{m} \times 5 \mu \mathrm{m}$. The microscopic images were obtained at a resolution of $256 \times 256$. Membrane samples were attached to the metal sample discs using adhesive carbon tabs (SPI Supplies Division of Structure Probe Inc., West Chester, PA, USA). The AFM images were obtained for three samples of each material. The measurements were all carried out under ambient conditions using the tapping mode of imaging.

\subsubsection{Water Adsorption}

Water adsorption was determined by the gravimetric method. A sample of a certain size was cut out from the obtained polymer. The resulting sample was weighed on an analytical balance. The measuring cup loaded with distilled water before the sample was placed in water and fixed. After a specified amount of time, the samples were removed, the remaining water from the surface was removed using filter paper and the sample was weighed. Water adsorption (B) is calculated as a percentage using the following formula:

$$
B=\left(m_{s}-m\right) / m
$$

where $\mathrm{m}$ is the mass of the sample before the test, $\mathrm{g}$; and $\mathrm{m}_{\mathrm{s}}$ is the mass of the sample after the test. The arithmetic average of the results of the five tests was determined as the main result.

\subsubsection{Permeability Measurements}

Single gas permeances tests through the obtained membranes (polymeric films) were performed according to the Daynes-Barrer technique in a constant-volume variable-pressure apparatus for gas permeability measurements at the initial transmembrane pressure difference of $110 \mathrm{kPa}$ and at ambient temperature $\left(25^{\circ} \mathrm{C}\right)$.

The experimental setup presented in Figure 2 was designed for high precision single gas time-lag permeation tests. The setup is comprised of a typical permeation cell made of AISI316 stainless steel with PTFE sealing, a vacuum turbomolecular station HiCube 80 Eco (Pfeiffer Vacuum, Asslar, Germany). The initial vacuum generated in the system was $4 \times 10^{-5} \mathrm{~Pa}$. The membrane area was $2.54 \mathrm{~cm}^{2}$. The feed-and permeate-side pressures were monitored by high precision pressure sensors PT 5000 (A-Flow, Paris, France) at an accuracy of $0.5 \%$ of the span (for the feed side) and MKS Baratron 750B 0-100 torr pressure transducer (MKS Instruments, Andover, MA, USA) with an accuracy of 1\% of the reading (for the permeate side). The constant feed pressure was maintained at $110 \mathrm{kPa}$ and the permeate pressure evolution was recorded with a sampling rate of $10 \mathrm{~ms}$. Each single gas test was repeated at least three times. A radial membrane permeation cell (position 1 on Figure 2) with a porous mechanical support was used, which was vacuum-degassed before each measurement.

The single gas permeability coefficients for helium, nitrogen, methane, carbon dioxide, hydrogen sulfide and ammonia through each sample were measured at least three times. After the ammonia analysis, the permeability coefficients of helium and nitrogen were measured again to evaluate the chemical resistance of polymer. All experiments were carried out following safety precautions, which are specified in ISO/TC 58/SC 4 and ISO/TC 161. After the investigation of ammonia gas transport properties, the permeability coefficients of helium and nitrogen did not change.

The permeability coefficient $\mathrm{P}$ was calculated according to:

$$
\mathrm{P}=\frac{\mathrm{Vp}_{2} \mathrm{~T}_{0}}{\mathrm{~V}_{\mathrm{m}} \mathrm{P}_{0} \mathrm{~T}} \frac{1}{\mathrm{~S} \tau\left(\mathrm{p}_{1}-\mathrm{p}_{2}\right)}
$$


where $\mathrm{V}$ is the permeate side volume, $\mathrm{m}^{3} ; \mathrm{V}_{\mathrm{m}}$ is the molar volume, $\mathrm{m}^{3} / \mathrm{mol} ; \mathrm{p}_{2}$ is the permeate side pressure for each individual experiment, $\mathrm{Pa} ; \mathrm{p}_{1}$ is the feed side pressure, $\mathrm{Pa} ; \mathrm{P}_{0}$ is the atmospheric pressure, $\mathrm{Pa} ; \mathrm{T}$ is the temperature, $\mathrm{K} ; \mathrm{T}_{0}$ is the $273.15, \mathrm{~K} ; \mathrm{S}$ is the membrane area, $\mathrm{m}^{2} ; 1$ is the membrane thickness, $\mathrm{m}$; and $\tau$ is the time of experiment, $\mathrm{s}$.

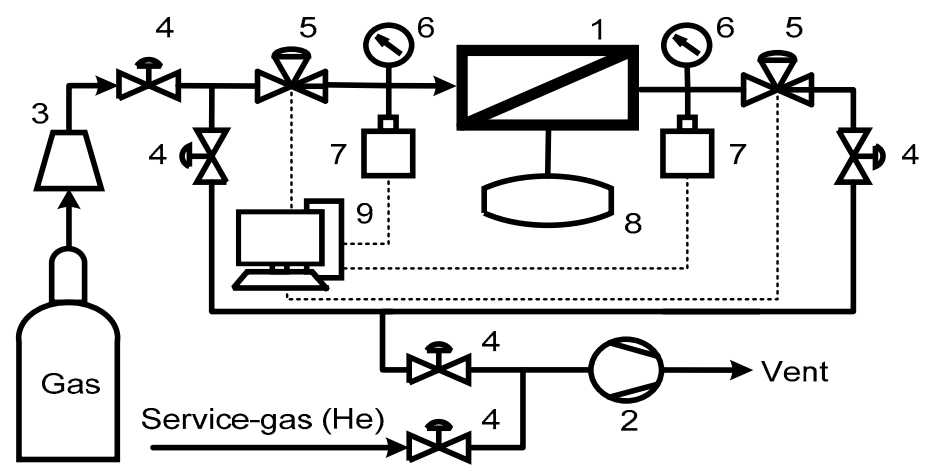

Figure 2. Schematic of experimental setup for single gas permeability test: $1=$ permeation cell; $2=$ vacuum station; 3 = pressure reducer; $4=$ manual valves; $5=$ pneumatic valves; 6 = pressure gauges; $7=$ pressure transducers; $8=$ additional volume for the permeate side; and $9=$ workstation.

\section{Results and Discussion}

\subsection{Polymer Characterization}

It was determined that when the peripheral polyoxyethylene blocks (polyoxypropylene glycol-4000 containing potassium-alcoholate end groups) were not found in MI, the reaction was accompanied by the formation of a glassy polymer product, regardless of the cocatalysts used, and lower temperatures. In that case, polyisocyanurates (PIR) were exclusively formed (Figure 3), according to the FTIR spectra (the presence of analytical bands in the region of 1410 and $1710 \mathrm{~cm}^{-1}$ ).

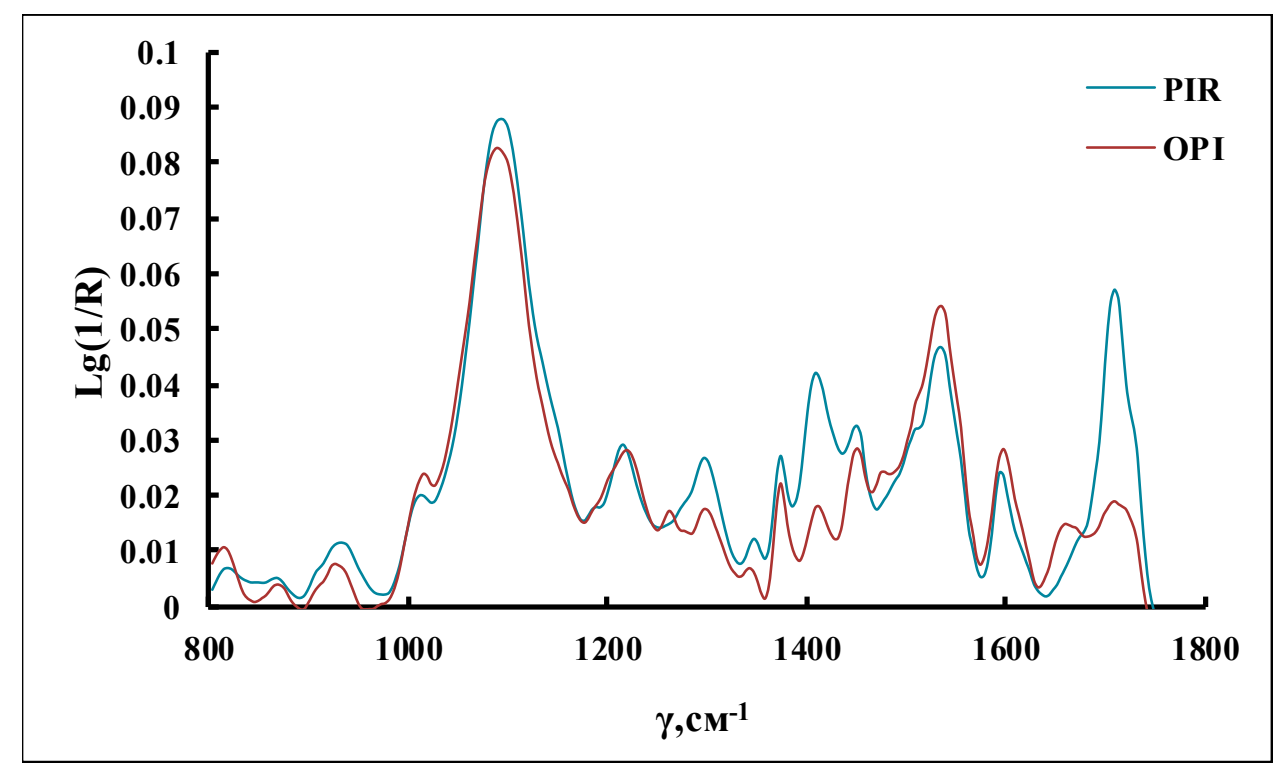

Figure 3. FTIR spectra of the polymers.

When MI containing 100\% of POE blocks (polyoxyethyleneglycol-4000, containing potassiumalcoholate end groups) is used, the polymer products formed exhibit significant hydrophilicity, low strength characteristics and high plastic deformation. In that case, the formation of O-polyisocyanate structural elements does not occur according to FTIR spectroscopy. 
Previous studies $[39,40]$ examined the effect of the molecular weight of block copolymers of propylene and ethylene oxides (the content of peripheral POE blocks was kept constant at $30 \%$ for PPEG with molecular weights of 3000, 4200 and $6000 \mathrm{~g} / \mathrm{mol}$ ) on the efficiency of the opening of isocyanate groups as activated on the carbonyl component. They found that the most favorable conditions for the formation of O-polyisocyanate (OPI) structural elements were present when a PPEG with a molecular weight of $4200 \mathrm{~g} / \mathrm{mol}$ were used. Factors affecting the polyaddition accompanied by the opening of isocyanate groups via the carbonyl component include the use of catalytic amounts of acidic compounds, water in combination with trimethylamine and maintenance of fairly low temperatures [49].

Therefore, the PPEGs with a molecular weight of $4200 \mathrm{~g} / \mathrm{mol}$ were used to study the effect of the content of peripheral POE blocks on the opening of $\mathrm{NCO}$ groups along the $\mathrm{C}=\mathrm{O}$ link. According to FTIR spectroscopic studies, a change in the content of POE blocks in PPEG from 15 to $30 \%$ does not affect the character of the spectra. The bands in the region of 1710 and $1410 \mathrm{~cm}^{-1}$ corresponding to the stretching vibrations of the $\mathrm{C}=\mathrm{O}$ bond are practically absent but a band appeared in the region of $1670 \mathrm{~cm}^{-1}$ that corresponds to the stretching vibrations of $\mathrm{N}=\mathrm{C}$ bonds in O-polyisocyanates (Figure 3). A shoulder observed at $1620 \mathrm{~cm}^{-1}$ indicated the formation of urea.

Thus, the presence of terminal POE is a prerequisite for the activation of isocyanate groups under the influence of MI on TDI with their subsequent opening by the carbonyl component. In this regard, the next studies were carried out for polymers obtained on the basis of TDI and PPEG, which contain $15,20,30$ and $40 \mathrm{wt} \%$ of POE blocks.

\subsubsection{Thermal and Thermomechanical Behavior}

According to the measurements of the thermogravimetric analysis curves (Figure 4), a decrease in the content of POE blocks practically does not affect the thermal stability of polymers.

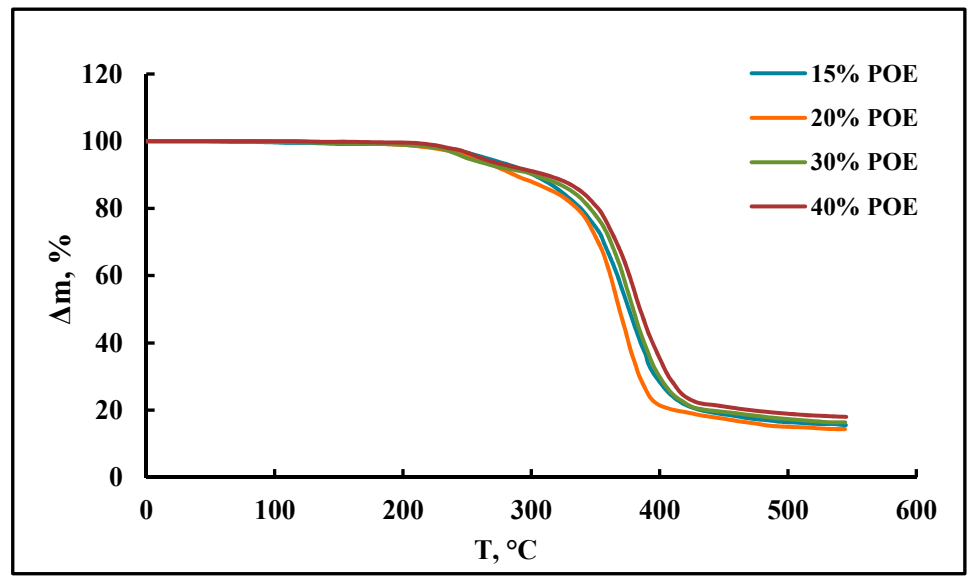

Figure 4. TGA profiles of polymers.

The curves of thermomechanical analysis (Figure 5) reflect the complexity of the macromolecular and supramolecular organization of the polymers that are being studied. Indeed, the question is about the block copolymers of polyethers and O-polyisocyanates. In turn, the flexible chain (polyether) component represents the block copolymers of propylene and ethylene oxides. Therefore, several relaxation processes are observed on TMA curves, which are significantly influenced by the content of POE blocks in PPEG. With an increase in the weight percentage of POE blocks, a shift in the onset of deformation to a lower temperature region is observed. The observed changes in TMA curves confirm the conclusion that a decrease in the content of POE blocks leads to more rigid packaging of O-polyisocyanate blocks. 


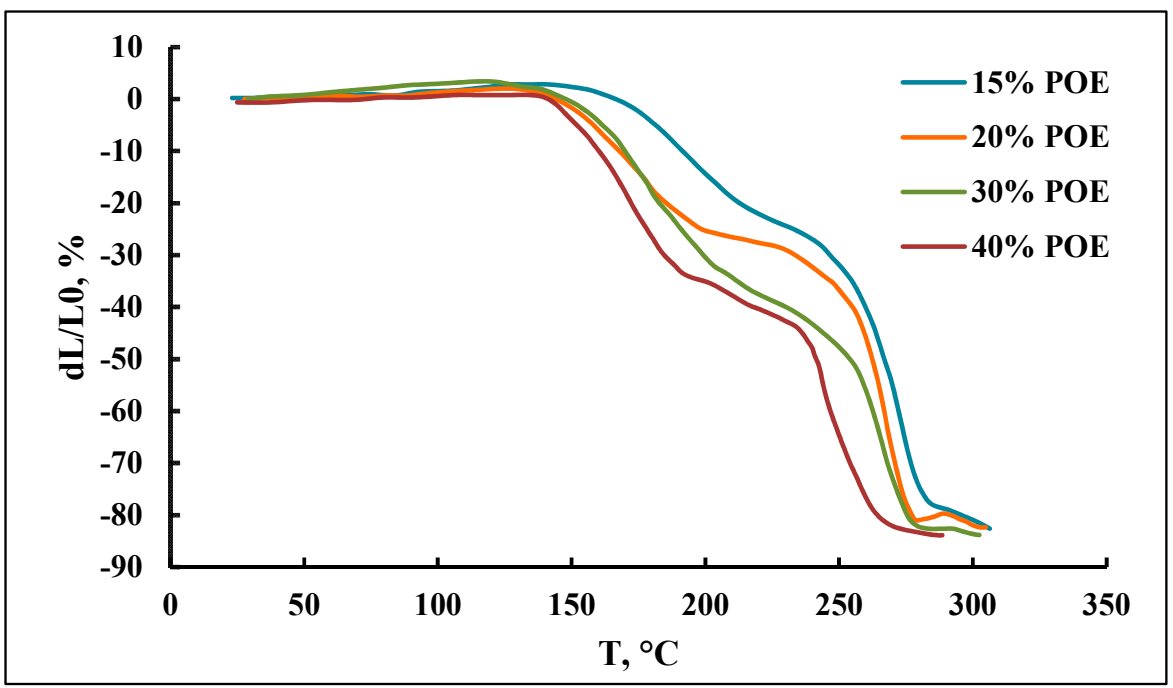

Figure 5. The curves of thermomechanical analysis of polymers.

In addition, the findings indicate that O-polyisocyanate blocks are the main element of the supramolecular organization of the studied polymers. The domains formed with their participation are distinguished by their stability in high temperatures. Thus, for the polymer obtained at $15 \mathrm{wt} \%$ of POE content, the deformation values of $20 \%$ are achieved only at $250{ }^{\circ} \mathrm{C}$.

The deformation of the samples, which accompanies the temperature rise from $250{ }^{\circ} \mathrm{C}$, is connected with the processes of thermal destruction of polymers. The run of TMA analysis curves reflects the fact that the segregation of O-polyisocyanate blocks is not due to the intermolecular interactions of physical nature but is instead due to the fact that urea is formed as a result of the involvement in its formation of NCO groups of ortho-position TDI, which are included into adjacent O-polyisocyanate blocks.

\subsubsection{Mechanical Behavior}

A change in the content of POE blocks leads to noticeable changes in the mechanical behavior of polymers (Figure 6). In this case, there is a change in the run of the curves and a regular increase in the relative elongation at the break of the samples with an increase in the percentage of POE blocks, which reflects the differences in their supramolecular organization. Such changes in the mechanical properties of block copolymers are the consequence of differences in their macromolecular structure. If the POE block content is $15 \mathrm{wt} \%$, the polyoxypropylene segments are located in the internal cavity of voids formed by O-polyisocyanate blocks. When the POE block content is $30 \mathrm{wt} \%$, the flexible chain component forms its own microphase outside the segregation zone of the rigid O-polyisocyanate blocks. As a result, the framework of the supramolecular structure of the resulting block copolymers decreases, leading to an increase in the relative elongation of the film polymer samples at the break.

It is suggested that during the formation of the cellular supramolecular structure of the synthesized microporous block copolymers, the internal component of the pore depends on the content of POE blocks in the initial macroinitiator. Thus, when the content of POE blocks in PPEG is $15-20 \mathrm{wt} \%$, part of the pore cavity is filled with polyoxypropylene segments. When the content of POE blocks in PPEG is $30 \mathrm{wt} \%$, the surface of the pores is composed of O-polyisocyanate blocks. In these cases, the obtained microporous polymers adsorb water without changing their geometric dimensions. An increase in the content of POE to $40 \mathrm{wt} \%$ leads to the swelling of polymer samples in water and the destruction of the cellular supramolecular structure due to the hydrophilicity of the polyoxyethylene segments (Figure 7). 


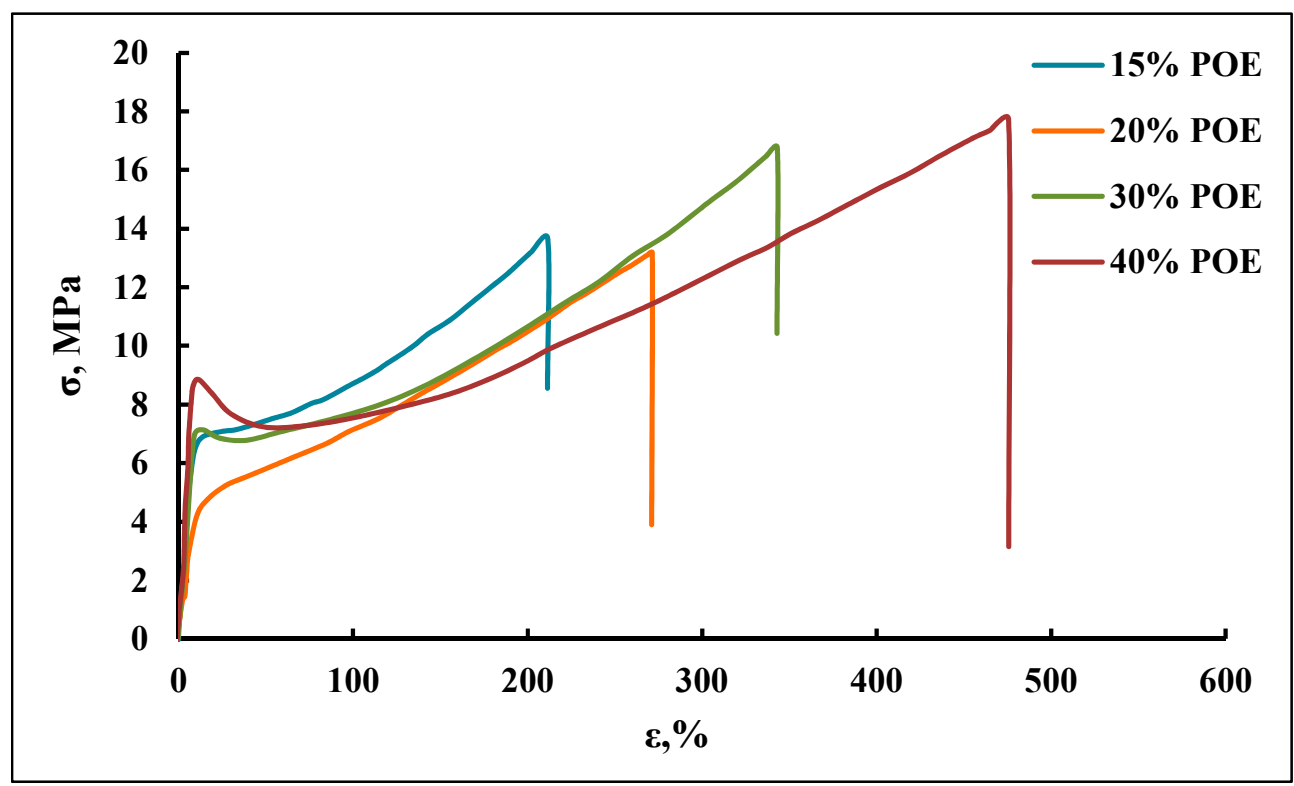

Figure 6. Tensile tests of polymers.

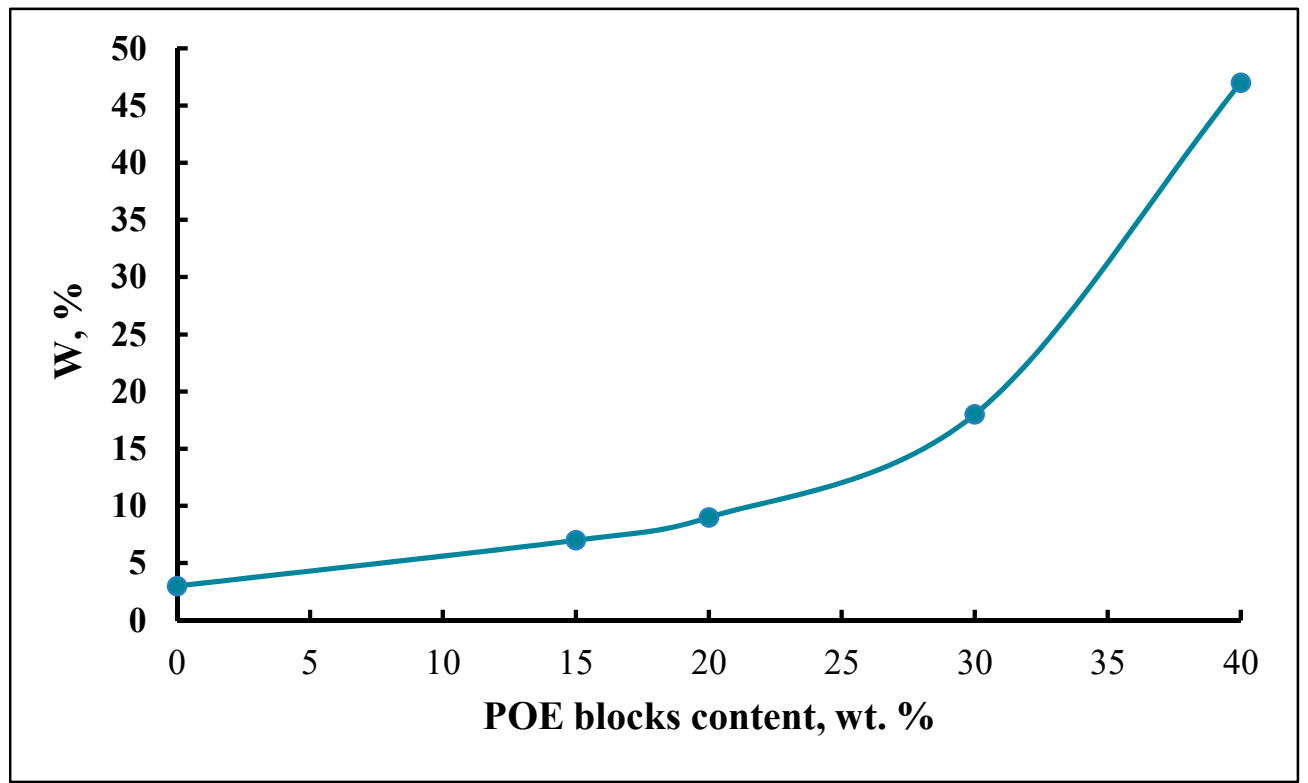

Figure 7. Dependence of the limiting degree of water adsorption $(\mathrm{W}, \%)$ of polymers on the POE block content (wt \%).

\subsubsection{Polymer Surface Morphology}

According to the AFM data (Figure 8), the content of POE blocks affects the morphology surface and cavity size. When the content of POE blocks is $20 \mathrm{wt} \%$, the cavity diameter is minimal. When the content of POE blocks is $30 \mathrm{wt} \%$, the cavity diameter increases. The AFM images allowed us to establish that an increase in the POE block content has a disproportionate influence on the nature of changes in the surface morphology of polymers, including the diameter of cavities. Thus, when the POE block content changes from 15 to $20 \%$, the diameter of cavities decreases. When the content of POE blocks is $20 \mathrm{wt} \%$, the cavity diameter is minimal. When the content of the POE is $30 \mathrm{wt} \%$, the cavity diameter significantly increases. In this case, the surface morphology also changes. This is a consequence of the fact that the change in the chemical structure of the flexible chain component in the block copolymer, including coplanar rigid O-polyisocyanate blocks, has a significant impact on the process of their segregation in the macromolecular space. 


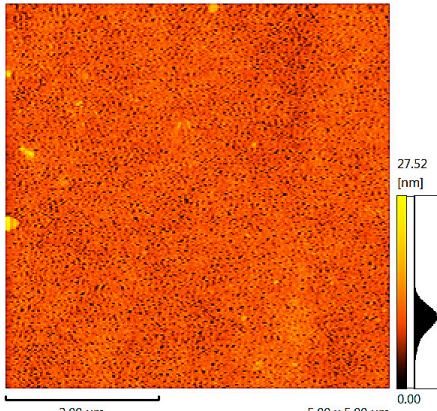

$5.00 \times 5.00$ un

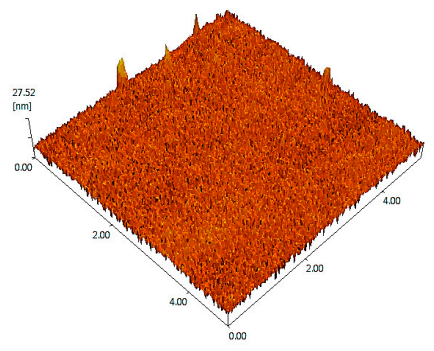

$5.00 \times 5.00$ [uml $Z$ Z $0.00-27.52$ [nm

(1)
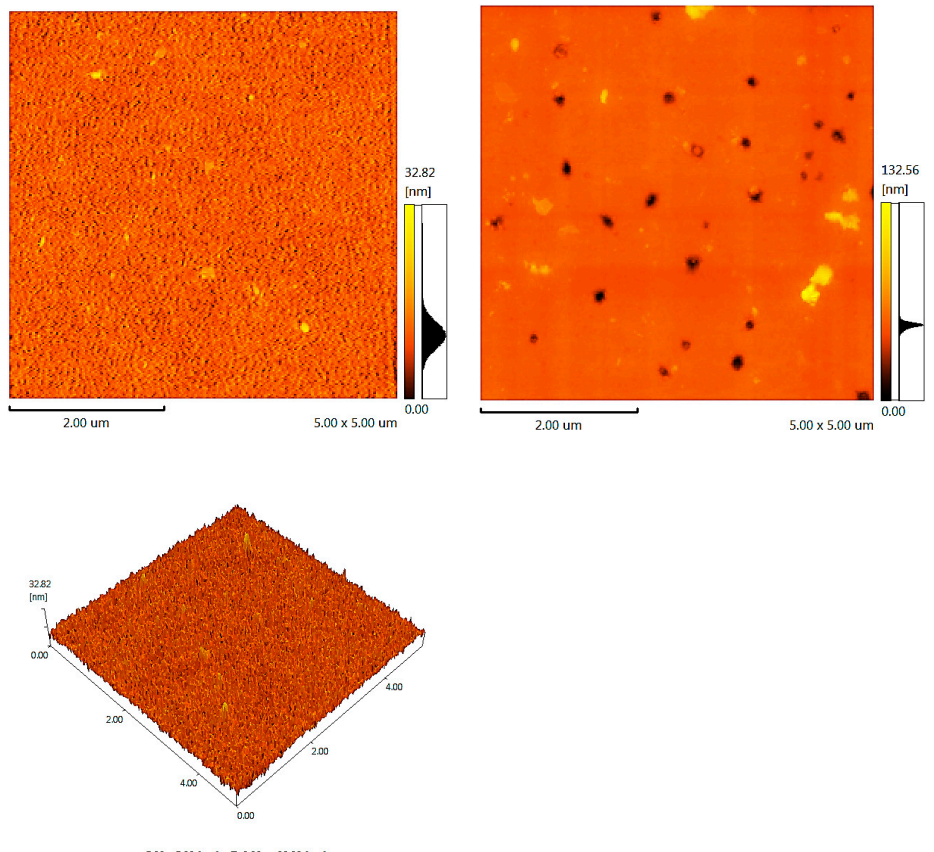

(2)
(3)

Figure 8. Atomic force microscopy of polymers. The content of POE blocks (wt \%) is 15 (1); 20 (2); and 30 (3).

\subsection{Gas Transport Properties of Polymers}

According to the studies of gas transport characteristics (Tables 1-6) of the obtained polymer membrane materials, the permeability for polar molecules of ammonia and hydrogen sulfide significantly exceeds the permeability values obtained for the non-polar molecules of $\mathrm{He}, \mathrm{N}_{2}$ and $\mathrm{CH}_{4}$. A relatively high permeability is also observed for carbon dioxide. The fact that $\mathrm{CO}_{2}$ exhibits higher permeability compared to $\mathrm{He}, \mathrm{N}_{2}$ and $\mathrm{CH}_{4}$ is associated with the higher solubility of $\mathrm{CO}_{2}$ in polyoxyethylene and polyoxypropylene blocks compared to other gases. This hypothesis is also confirmed by the higher sorption coefficients for $\mathrm{CO}_{2}$ in comparison with $\mathrm{He}, \mathrm{N}_{2}$ and $\mathrm{CH}_{4}$ (Table 3). At the same time, the content of POE blocks has a small effect on the permeability for all studied gases. The observed non-monotonous changes in permeability can be explained by the fact that a change in the content of POE blocks leads to significant changes in the packing of the flexible chain component inside of the voids and outside of the segregation of the coplanar O-polyisocyanate blocks. This is why there are not trends formed after increasing the POE content in the obtained polymer. This might also be the reason for the higher diffusion coefficient of the larger molecule of methane compared to the smaller molecule of helium in the case of $20 \%$ POE. It is also clear that the solubility coefficient of reactive (acid and base) gases, such as carbon dioxide, hydrogen sulfide and ammonia, is higher than that of helium, nitrogen and methane due to their chemical affinity to the polymeric materials.

Table 1. Polymer permeability coefficient (P) for different single gases obtained at different POE block contents (measurements are given at the pressure of $1 \mathrm{~atm}$ ).

\begin{tabular}{ccccccc}
\hline \multirow{2}{*}{$\begin{array}{c}\text { POE Content, } \\
\text { wt \% }\end{array}$} & $\mathbf{H e}$ & $\mathbf{N}_{\mathbf{2}}$ & $\mathbf{C H}_{\mathbf{4}}$ & $\mathbf{C O}_{\mathbf{2}}$ & $\mathbf{N H}_{\mathbf{3}}$ & $\mathbf{H}_{\mathbf{2}} \mathbf{S}$ \\
\cline { 2 - 7 } & 11 & 1.5 & 3 & 110 & 587 & 507 \\
15 & 5.5 & 1.7 & 12 & 134 & 563 & 520 \\
20 & 19 & 3.1 & 11 & 102 & 489 & 454 \\
30 & 17 & 2 & 8 & 117 & 693 & 657 \\
40 & 1 Barrer $=3.346 \times 10^{-16} \mathrm{~mol} \cdot \mathrm{m} \cdot \mathrm{m}^{-2} \cdot \mathrm{s}^{-1} \cdot \mathrm{Pa}^{-1}$.
\end{tabular}


Table 2. Diffusion coefficients (D) of polymer obtained at different POE block contents.

\begin{tabular}{ccccccc}
\hline \multirow{2}{*}{$\begin{array}{c}\text { POE Content, } \\
\text { wt \% }\end{array}$} & $\mathbf{5 e}$ & $\mathbf{N}_{\mathbf{2}}$ & $\mathbf{C H}_{\mathbf{4}}$ & $\mathbf{C O}_{\mathbf{2}}$ & $\mathbf{N H}_{\mathbf{3}}$ & $\mathbf{H}_{\mathbf{2}} \mathbf{S}$ \\
\cline { 2 - 7 } & 0.10 & 0.02 & 0.06 & 0.28 & 0.30 & 0.33 \\
15 & 0.22 & 0.22 & 0.36 & 0.71 & 0.62 & 0.66 \\
20 & 0.99 & 0.24 & 0.53 & 2.73 & 2.37 & 3.10 \\
30 & 0.84 & 0.28 & 0.54 & 2.89 & 3.08 & 4.62 \\
40 & &
\end{tabular}

Table 3. Sorption coefficients (S) of polymer obtained at different POE block contents.

\begin{tabular}{ccccccc}
\hline \multirow{2}{*}{$\begin{array}{c}\text { POE Content, } \\
\text { wt \% }\end{array}$} & \multicolumn{5}{c}{$\mathbf{S}, \mathbf{1 0}^{-\mathbf{5}}, \mathbf{~} \mathbf{~ o l} /\left(\mathbf{m}^{\mathbf{3}} \cdot \mathbf{P a}\right)$} \\
\cline { 2 - 7 } & $\mathbf{H e}$ & $\mathbf{N}_{\mathbf{2}}$ & $\mathbf{C H}_{\mathbf{4}}$ & $\mathbf{C O}_{\mathbf{2}}$ & $\mathbf{N H}_{\mathbf{3}}$ & $\mathbf{H}_{\mathbf{2}} \mathbf{S}$ \\
\hline 15 & 35 & 21 & 18 & 133 & 665 & 510 \\
20 & 8.5 & 3 & 11 & 63 & 303 & 264 \\
30 & 65 & 44 & 72 & 125 & 690 & 381 \\
40 & 67 & 23 & 48 & 136 & 755 & 476 \\
\hline
\end{tabular}

Table 4. Ideal selectivity for $\mathrm{NH}_{3}$ /gas systems for polymer membranes obtained at different POE block contents.

\begin{tabular}{|c|c|c|c|c|c|c|c|c|c|c|c|c|c|c|c|}
\hline \multirow{2}{*}{$\begin{array}{l}\text { POE Content, } \\
\text { wt } \%\end{array}$} & \multicolumn{3}{|c|}{$\mathrm{NH}_{3} / \mathrm{He}$} & \multicolumn{3}{|c|}{$\mathrm{NH}_{3} / \mathrm{N}_{2}$} & \multicolumn{3}{|c|}{$\mathrm{NH}_{3} / \mathrm{CH}_{4}$} & \multicolumn{3}{|c|}{$\mathrm{NH}_{3} / \mathrm{CO}_{2}$} & \multicolumn{3}{|c|}{$\mathrm{NH}_{3} / \mathrm{H}_{2} \mathrm{~S}$} \\
\hline & $\alpha_{\text {perm }}$ & $\alpha_{\text {diff }}$ & $\alpha_{\text {sorp }}$ & $\alpha_{\text {perm }}$ & $\alpha_{\text {diff }}$ & $\alpha_{\text {sorp }}$ & $\alpha_{\text {perm }}$ & $\alpha_{\text {diff }}$ & $\alpha_{\text {sorp }}$ & $\alpha_{\text {perm }}$ & $\alpha_{\text {diff }}$ & $\alpha_{\text {sorp }}$ & $\alpha_{\text {perm }}$ & $\alpha_{\text {diff }}$ & $\alpha_{\text {sorp }}$ \\
\hline 15 & 55 & 3 & 19 & 376 & 12 & 32 & 194 & 5 & 38 & 5 & 1.06 & 5 & 1.16 & 0.89 & 1.30 \\
\hline 20 & 101 & 3 & 36 & 329 & 3 & 115 & 48 & 2 & 28 & 4 & 0.88 & 5 & 1.08 & 0.94 & 1.15 \\
\hline 30 & 26 & 2 & 11 & 158 & 10 & 16 & 43 & 4.5 & 10 & 5 & 0.87 & 5,5 & 1.08 & 0.60 & 1.81 \\
\hline 40 & 41 & 4 & 11 & 352 & 11 & 33 & 89 & 6 & 16 & 6 & 1.07 & 5.5 & 1.06 & 0.67 & 1.59 \\
\hline
\end{tabular}

Table 5. Ideal selectivity for $\mathrm{CO}_{2}$ /gas systems for polymer membranes obtained at different POE block contents.

\begin{tabular}{|c|c|c|c|c|c|c|c|c|c|c|c|c|c|c|c|}
\hline \multirow{2}{*}{$\begin{array}{l}\text { POE Content, } \\
\text { wt } \%\end{array}$} & \multicolumn{3}{|c|}{$\mathrm{CO}_{2} / \mathrm{He}$} & \multicolumn{3}{|c|}{$\mathrm{CO}_{2} / \mathrm{N}_{2}$} & \multicolumn{3}{|c|}{$\mathrm{CO}_{2} / \mathrm{CH}_{4}$} & \multicolumn{3}{|c|}{$\mathrm{CO}_{2} / \mathrm{NH}_{3}$} & \multicolumn{3}{|c|}{$\mathrm{CO}_{2} / \mathrm{H}_{2} \mathrm{~S}$} \\
\hline & $\alpha_{\text {perm }}$ & $\alpha_{\text {diff }}$ & $\alpha_{\text {sorp }}$ & $\alpha_{\text {perm }}$ & $\alpha_{\text {diff }}$ & $\alpha_{\text {sorp }}$ & $\alpha_{\text {perm }}$ & $\alpha_{\text {diff }}$ & $\alpha_{\text {sorp }}$ & $\alpha_{\text {perm }}$ & $\alpha_{\text {diff }}$ & $\alpha_{\text {sorp }}$ & $\alpha_{\text {perm }}$ & $\alpha_{\text {diff }}$ & $\alpha_{\text {sorp }}$ \\
\hline 15 & 10 & 2 & 4 & 71 & 11 & 6 & 36 & 5 & 7.5 & 0.19 & 0.94 & 0.20 & 0.22 & 0.84 & 0.26 \\
\hline 20 & 24 & 3 & 7 & 78 & 3 & 24 & 11 & 2 & 6 & 0.24 & 1.14 & 0.21 & 0.26 & 1.07 & 0.24 \\
\hline 30 & 5 & 3 & 2 & 33 & 11.5 & 2 & 9 & 5 & 2 & 0.21 & 1.15 & 0.18 & 0.22 & 0.69 & 0.33 \\
\hline 40 & 7 & 3 & 2 & 60 & 10 & 6 & 15 & 5 & 3 & 0.17 & 0.94 & 0.18 & 0.18 & 0.62 & 0.29 \\
\hline
\end{tabular}

Table 6. Ideal selectivity for $\mathrm{H}_{2} \mathrm{~S}$ /gas systems for polymer membranes obtained at different POE block contents.

\begin{tabular}{|c|c|c|c|c|c|c|c|c|c|c|c|c|c|c|c|}
\hline \multirow{2}{*}{$\begin{array}{l}\text { POE Content, } \\
\text { wt } \%\end{array}$} & \multicolumn{3}{|c|}{$\mathrm{H}_{2} \mathrm{~S} / \mathrm{He}$} & \multicolumn{3}{|c|}{$\mathrm{H}_{2} \mathrm{~S} / \mathrm{N}_{2}$} & \multicolumn{3}{|c|}{$\mathrm{H}_{2} \mathrm{~S} / \mathrm{CH}_{4}$} & \multicolumn{3}{|c|}{$\mathrm{H}_{2} \mathrm{~S} / \mathrm{CO}_{2}$} & \multicolumn{3}{|c|}{$\mathrm{H}_{2} \mathrm{~S} / \mathrm{NH}_{3}$} \\
\hline & $\alpha_{\text {perm }}$ & $\alpha_{\text {diff }}$ & $\alpha_{\text {sorp }}$ & $\alpha_{\text {perm }}$ & $\alpha_{\text {diff }}$ & $\alpha_{\text {sorp }}$ & $\alpha_{\text {perm }}$ & $\alpha_{\text {diff }}$ & $\alpha_{\text {sorp }}$ & $\alpha_{\text {perm }}$ & $\alpha_{\text {diff }}$ & $\alpha_{\text {sorp }}$ & $\alpha_{\text {perm }}$ & $\alpha_{\text {diff }}$ & $\alpha_{\text {sorp }}$ \\
\hline 15 & 48 & 3 & 14.5 & 325 & 13 & 24 & 167 & 5 & 29 & 5 & 1.19 & 4 & 0.86 & 1.13 & 0.77 \\
\hline 20 & 93 & 3 & 31 & 304 & 3 & 101 & 44 & 2 & 24 & 4 & 0.93 & 4 & 0.93 & 1.06 & 0.87 \\
\hline 30 & 24 & 4 & 6 & 147 & 17 & 9 & 40 & 8 & 5 & 5 & 1.46 & 3 & 0.93 & 1.68 & 0.55 \\
\hline 40 & 39 & 5.5 & 7 & 334 & 16 & 21 & 84 & 8.5 & 10 & 6 & 1.60 & 3.5 & 0.95 & 1.5 & 0.63 \\
\hline
\end{tabular}

It is important to note the high values of ideal selectivity for pairs of gases, including polar and non-polar molecules.

The diffusion coefficient increases with an increase in the POE block content in PPEG for all studied gases. These regularities are consistent with the stated assumption that the voids of polymers obtained with a low content of POE blocks are filled with a polyoxypropylene component. As a result, the space inside the pores is reduced. Therein, for non-polar gases, an obstacle appears due to the imperfection of the channel formation between the pores.

In the case of polar gases, these penetrate as a result of their sorption by chemical substances and subsequently fill the surface of the pores. At the same time, the values of the sorption coefficients for polar gases enormously exceed those for non-polar gases (Table 3). 
The established differences in the permeability values turned out to be the cause of the high ideal selectivity for $\mathrm{NH}_{3} / \mathrm{CH}_{4}, \mathrm{H}_{2} \mathrm{~S} / \mathrm{CH}_{4}, \mathrm{CO}_{2} / \mathrm{CH}_{4}, \mathrm{NH}_{3} / \mathrm{N}_{2}, \mathrm{H}_{2} \mathrm{~S} / \mathrm{He}, \mathrm{H}_{2} \mathrm{~S} / \mathrm{N}_{2}, \mathrm{CO}_{2} / \mathrm{He}, \mathrm{NH}_{3} / \mathrm{He}$ and $\mathrm{CO}_{2} / \mathrm{N}_{2}$ pairs at a POE block content of 15-20 and relatively high ideal selectivity for $\mathrm{NH}_{3} / \mathrm{CO}_{2}$ and $\mathrm{H}_{2} \mathrm{~S} / \mathrm{CO}_{2}$ pairs. Moreover, the obtained results for $\mathrm{CO}_{2} / \mathrm{N}_{2}$ hold promise in comparison with the data presented on the revised upper bond of Robeson plot [50], especially for the case of 20\% POE. For $\mathrm{CO}_{2} / \mathrm{CH}_{4}$, the best results are obtained with $15 \%$ POE but this is slightly lower than the upper bond.

The ability to select the necessary ideal selectivity of the resulting polymer membranes by changing the POE block content in PPEG is important from a practical perspective.

\section{Conclusions}

In this present work, the influence of the content of peripheral POE blocks in PPEG on supramolecular structure processes and gas transport characteristics of polymers obtained on the basis of PPEG and TDI was investigated. The presence of peripheral POE blocks in PPEG is a prerequisite for the activation of isocyanate groups under the influence of MI on TDI, with their subsequent opening by the carbonyl component and formation of O-polyisocyanate blocks.

Several relaxation processes are observed on TMA curves, which are significantly influenced by the content of POE blocks in PPEG. With an increase in the weight percentage of POE blocks, a shift in the onset of deformation to lower temperatures is observed. The observed changes in TMA curves confirm the conclusion that a decrease in the content of POE blocks leads to more rigid packaging of O-polyisocyanate blocks.

From the results obtained in this work, it can be inferred that if the POE block content is $15 \mathrm{wt} \%$, the polyoxypropylene segments are located in the internal cavity of voids formed by O-polyisocyanate blocks. When the POE block content is $30 \mathrm{wt} \%$, the flexible chain component forms its own microphase outside the segregation zone of the rigid O-polyisocyanate blocks.

The permeability for the polar molecules of ammonia and hydrogen sulfide significantly exceeds the permeability values obtained for non-polar molecules of $\mathrm{He}, \mathrm{N}_{2}$ and $\mathrm{CH}_{4}$. A relatively high permeability is also observed for carbon dioxide. At the same time, the content of POE blocks has a small effect on the permeability for all studied gases. The diffusion coefficient increases with an increase in the POE block content in PPEG for all studied gases.

Author Contributions: The synthesis of PPEG carried out by R.R.S. The polymers preparation and characterization were performed by A.I.M., I.I.Z. and R.S.D. Gas transport properties investigation were performed by A.A.A. The AFM characterization of polymers was performed by T.S.S., I.M.D. and I.V.V. wrote the manuscript, supervised the work and revised the manuscript. All authors read and approved the final manuscript.

Funding: The research was funded by Russian Foundation for Basic research, grant t no. 19-03-00280 and the Ministry of science and higher education of the Russian Federation in the Framework of the Basic Part of the State Task, Project No. 4.6535.2017/8.9.

Conflicts of Interest: The authors declare no conflict of interest.

$\begin{array}{ll}\text { Abbreviations } & \\ \text { O-polyisocyanates (OPI) } & \text { polyisocyanate of acetal nature } \\ \text { TDI } & \text { 2,4-toluene diisocyanate } \\ \text { MI } & \text { macroinitiator } \\ \text { PPEG } & \text { potassium-substituted block copolymers of propylene and ethylene oxide } \\ \text { POE } & \text { polyoxyethylene } \\ \text { FTIR } & \text { Fourier transform infrared spectroscopy analysis } \\ \text { TMA } & \text { thermomechanical analysis } \\ \text { TGA } & \text { thermal gravimetric analysis } \\ \text { AFM } & \text { atomic force microscopy } \\ \text { PIR } & \text { polyisocyanurates }\end{array}$




\section{References}

1. Vorotyntsev, V.M. High purification of gases by diffusion through polymer membranes. Pet. Chem. 2015, 55, 259-275. [CrossRef]

2. Atlaskin, A.A.; Trubyanov, M.M.; Yanbikov, N.R.; Vorotyntsev, A.V.; Drozdov, P.N.; Vorotyntsev, V.M.; Vorotyntsev, I.V. Comprehensive experimental study of membrane cascades type of "continuous membrane column" for gases high-purification. J. Membr. Sci. 2019, 572, 92-101. [CrossRef]

3. Trubyanov, M.M.; Drozdov, P.N.; Atlaskin, A.A.; Battalov, S.V.; Puzanov, E.S.; Vorotyntsev, A.V.; Petukhov, A.N.; Vorotyntsev, V.M.; Vorotyntsev, I.V. Unsteady-state membrane gas separation by novel pulsed retentate mode for improved membrane module performance: Modelling and experimental verification. J. Membr. Sci. 2017, 530, 53-64. [CrossRef]

4. Atlaskin, A.A.; Trubyanov, M.M.; Yanbikov, N.R.; Bukovsky, M.V.; Drozdov, P.N.; Vorotyntsev, V.M.; Vorotyntsev, I.V. Total Reflux Operating Mode of Apparatuses of a Membrane Column Type during High Purification of Gases to Remove a Highly Permeable Impurity. Pet. Chem. 2018, 58, 508-517. [CrossRef]

5. Akhmetshina, A.A.; Davletbaeva, I.M.; Grebenschikova, E.S.; Sazanova, T.S.; Petukhov, A.N.; Atlaskin, A.A.; Razov, E.N.; Zaripov, I.I.; Martins, C.F.; Neves, L.A.; Vorotyntsev, I.V. The Effect of Microporous Polymeric Support Modification on Surface and Gas Transport Properties of Supported Ionic Liquid Membranes. Membranes 2015, 6, 4. [CrossRef] [PubMed]

6. Davletbaeva, I.M.; Emelina, O.Y.; Vorotyntsev, I.V.; Davletbaev, R.S.; Grebennikova, E.S.; Petukhov, A.N.; Akhmetshina, A.I.; Sazanova, T.S.; Loskutov, V.V. Synthesis and properties of novel polyurethanes based on amino ethers of boric acid for gas separation membranes. RSC Adv. 2015, 5, 65674-65683. [CrossRef]

7. Vorotyntsev, V.M.; Drozdov, P.N.; Vorotyntsev, I.V.; Anikin, A.E.; Beljaev, E.M.; Soboleva, Y.A. The physico-chemical bases of separation and high purification of fluorocarbons and simple gases. Pet. Chem. 2011, 51, 492-495. [CrossRef]

8. Davletbaeva, I.M.; Nurgaliyeva, G.R.; Akhmetshina, A.I.; Davletbaev, R.S.; Atlaskin, A.A.; Sazanova, T.S.; Efimov, S.V.; Klochkov, V.V.; Vorotyntsev, I.V. Porous polyurethanes based on hyperbranched amino ethers of boric acid. RSC Adv. 2016, 6, 111109-111119. [CrossRef]

9. Akhmetshina, A.I.; Petukhov, A.N.; Vorotyntsev, A.V.; Nyuchev, A.V.; Vorotyntsev, I.V. Absorption Behavior of Acid Gases in Protic Ionic Liquid/Alkanolamine Binary Mixtures. ACS Sustain. Chem. Eng. 2017, 5, 3429-3437. [CrossRef]

10. Vorotyntsev, V.M.; Malyshev, V.M.; Vorotyntsev, I.V. High purification of gases by the hybrid gas hydratemembrane method. Pet. Chem. 2014, 54, 491-497. [CrossRef]

11. Akhmetshina, A.I.; Petukhov, A.N.; Mechergui, A.; Vorotyntsev, A.V.; Nyuchev, A.V.; Moskvichev, A.A.; Vorotyntsev, I.V. Evaluation of Methanesulfonate-Based Deep Eutectic Solvent for Ammonia Sorption. J. Chem. Eng. Data 2018, 63, 1896-1904. [CrossRef]

12. Odani, H.; Taira, K.; Nemoto, N.; Kurata, M. Solubilities of inertgases in styrene-butadiene-styrene block copolymers. Bull. Inst. Chem. Res. 1975, 53, 409-423.

13. Csernica, J.; Badduor, R.F.; Cohen, R.E. Gas permeability of a polystyrene/polybutadiene block copolymer with oriented lamellar domains. Macromolecules 1987, 20, 2468-2471. [CrossRef]

14. Csernica, J.; Badduor, R.F.; Cohen, R.E. Gas permeability of a polystyrene/polybutadiene block copolymer possessing a misoriented lamellar morphology. Macromolecules 1989, 22, 1493-1496. [CrossRef]

15. Buonomenna, M.G.; Golemme, G.; Tone, C.M.; De Santo, M.P.; Ciuchi, F.; Perrotta, E. Nanostructured poly(styrene-b-butadiene-b-styrene) (SBS) membranes for the separation of nitrogen from natural gas. Adv. Funct. Mater. 2012, 22, 1759-1767. [CrossRef]

16. Lokaj, J.; Brozova, L.; Holler, P.; Pientka, Z. Synthesis and gas permeability of block copolymers composed of poly(styrene-coacrilonitrile) and polystyrene blocks. Collect. Czech. Chem. Commun. 2002, 67, 267-278. [CrossRef]

17. Buonemenna, M.G.; Yave, W.; Goleme, G. Some approaches for high performance polymer based membranes for gas separation: Block copolymers, carbon molecular sieves and mixed matrix membranes. RCS Adv. 2012, 2, 10745-10773. [CrossRef]

18. Patel, N.P.; Spontak, R.J. Mesoblends of polyether blockcopolymers with Poly(ethylene glycol). Macromolecules 2004, 37, 1394-1402. [CrossRef] 
19. Lee, H.S.; Roy, A.; Lane, O.; Dunn, S.; McGrath, J.E. Hydrophilic-hydrophobic multiblock copolymers based on poly(arylene ether sulfone) via low-temperature coupling reactions for proton exchange membrane fuel cells. Polymer 2008, 49, 715-723. [CrossRef]

20. Scholes, C.A.; Chen, G.Q.; Lu, H.T.; Kentish, S.E. Crosslinked PEG and Pebax Membranes for Concurrent Permeation of Water and Carbon Dioxide. Membranes 2016, 6, 1. [CrossRef]

21. Knight, P.M.; Lyman, D.J. Gas permeability of various block copolyether-urethanes. J. Membr. Sci. 1984, 17, 245-254. [CrossRef]

22. Isfahani, A.; Ghalei, B.; Bagheri, R.; Kinoshita, Y.; Kitagawa, H.; Sivaniah, E. Polyurethane Gas Separation Membranes with Ethereal Bonds in the Hard Segments. J. Membr. Sci. 2016, 513, 58-66. [CrossRef]

23. Nebipasagil, A.; Park, J.; Lane, O.; Sundell, B.; Mecham, S.; Freeman, B.; Riffle, J.; McGrath, J. Polyurethanes Containing Poly(arylene ether sulfone) and Poly(ethylene oxide) Segments for Gas Separation Membranes. Polymer 2017, 118, 256-267. [CrossRef]

24. Hsieh, K.H.; Tsai, C.C.; Chang, D.M. Vapor and gaspermeability of polyurethane membranes. Part II. Effect offunctional group. J. Membr. Sci. 1991, 56, 279-287. [CrossRef]

25. Osman, M.A.; Mittal, V.; Morbidelli, M.; Suter, U.W. Polyurethane Adhesive Nanocomposites as Gas Permeation Barrier. Macromolecules 2003, 36, 9851-9858. [CrossRef]

26. Pegoraro, M.; Zanderighi, L.; Penati, A.; Severini, F.; Bianchi, F.; Cao, N. Polyurethane membranes from polyether and polyester diols for gas fractionation. J. Appl. Polym. Sci. 1991, 43, 84-97. [CrossRef]

27. Xiao, H.; Ping, Z.H.; Xie, J.W.; Yu, T.Y. Permeation of $\mathrm{CO}_{2}$ through PU. J. Appl. Polym. Sci. 1990, 40, 9-23. [CrossRef]

28. McBride, J.S.; Massaro, T.A.; Cooper, S.L. Diffusion of gases through PU block polymers. J. Appl. Polym. Sci. 1979, 23, 14-31. [CrossRef]

29. Burke, A.; Hasirci, N. Polyurethanes in biomedical applications. Biomater. From Mol. Eng. Tissue. 2004, 553, 83-101.

30. Ho, B.; Choon, K.; Young, M. Gas separation properties of polysiloxane/polyether mixed soft segment urethane urea membranes. J. Memb. Sci. 2002, 204, 69-83.

31. Ulubayram, K.; Hasirci, N. Polyurethanes-Effect of Chemical-Composition on Mechanical-Properties and Oxygen Permeability. Polymer 1992, 33, 8-22. [CrossRef]

32. Wang, Y.; Gupta, M.; Schiraldi, D. Oxygen permeability in thermoplastic Pus. J. Polym. Sci. Part B Polym. Phys. 2012, 50, 93-111. [CrossRef]

33. Chattopadhyay, D.; Raju, K. Structural engineering of PU coatings for high performance applications. Prog. Polym. Sci. 2007, 32, 418-457. [CrossRef]

34. Chen, T.K.; Shieh, T.S.; Chui, J.Y. Studies on the first DSC endotherm of PU hard segment based on 4,4'-diphenylmethanediisocyanate and 1,4-butanediol. Macromolecules 1998, 31, 20-37. [CrossRef]

35. Wang, Z.; Wang, B.; Yang, Y.; Hu, C. Correlations between gas permeation and free-volume hole properties of PU membranes. Eur. Polym. J. 2003, 39, 9-20. [CrossRef]

36. Chen, C.; Han, B.; Li, J.; Shang, T.; Zou, J.; Jiang, W. A new model on the diffusion of small molecule penetrants in dense polymer membranes. J. Memb. Sci. 2001, 187, 18-31. [CrossRef]

37. Wang, Z.; Wang, B.; Qi, N.; Ding, X.; Hu, J. Free volume and water vapor permeability properties in PU membranes studied by positrons. Mater. Chem. Phys. 2004, 88, 6-17. [CrossRef]

38. Gisselfält, K.; Helgee, B. Effect of soft segment length and chain extender structure on phase separation and morphology in poly(urethane urea)s. Macromol. Mater. Eng. 2003, 288, 71-83. [CrossRef]

39. Mishra, A.; Maiti, P. Morphology of PUs at various length scale: The influence of chain structure. J. Appl. Polym. Sci. 2011, 120, 55-69. [CrossRef]

40. Maji, P.; Das, N.; Bhowmick, N. Preparation and properties of PU nanocomposites of novel architecture as advanced barrier materials. Polymer 2010, 51, 10-31. [CrossRef]

41. Stratigaki, M.; Choudalakis, G.; Gotsis, A.D. Gas transport properties in waterborne polymer nanocomposite coatings containing organomodified clays. J. Coatings Technol. Res. 2014, 11, 899-911. [CrossRef]

42. Talakesh, M.; Sadeghi, M.; Chenar, M.; Khosravi, A. Gas Separation Properties of Poly(ethylene glycol)/ Poly(tetramethylene glycol) Based Polyurethane Membranes. J. Membr. Sci. 2012, 415, 469-477. [CrossRef] 
43. Rahman, M.; Filiz, V.; Shishatskiy, S.; Abetz, C.; Georgopanos, P.; Khan, M.; Neumann, S.; Abetz, V. Influence of Poly(ethylene glycol) Segment Length on $\mathrm{CO}_{2}$ Permeation and Stability of Polyactive Membranes and Their Nanocomposites with PEG-POSS. ACS Appl. Mater. Interfaces 2015, 7, 12289-12298. [CrossRef] [PubMed]

44. Brinkmann, T.; Naderipour, C.; Pohlmann, J.; Wind, J.; Wolff, T.; Esche, E.; Müller, D.; Wozny, G.; Hoting, B. Pilot Scale Investigations of the Removal of Carbon Dioxide from Hydrocarbon Gas Streams Using Poly(ethylene oxide)-Poly(butylene terephthalate) Polyactive) Thin Film Composite Membranes. J. Membr. Sci. 2015, 489, 237-247. [CrossRef]

45. Davletbaeva, I.M.; Akhmetshina, A.I.; Davletbaev, R.S.; Zaripov, I.I.; Gumerova, A.M.; Sharifullin, R.R. Optically Transparent Mesoporous Polymers Based on Anionic Macroinitiators and 2,4-Toluylene Diisocyanate. Pol. Sci. Ser. 2014, 6, 781-788.

46. Davletbaev, R.; Akhmetshina, A.; Gumerov, A.; Davletbaeva, I.; Parfenov, V. Supramolecular Architecture of Polymers as the Basis of Obtaining Mesoporous Polymers. Compos. Interfaces 2014, 21, 611-621. [CrossRef]

47. Davletbaeva, I.M.; Shkodich, V.F.; Gumerov, A.M.; Emelina, O.Y.; Naumov, A.V. Intermolecular interactions in metal-containing polymers based on 2,4-toluylene diisocyanate and open-chain analogs of crown ethers. Pol. Sci. Ser. A 2010, 4, 392-397. [CrossRef]

48. Akhmetshina, A.I.; Davletbaev, R.S.; Davletbaeva, I.M.; Mikhailova, A.V.; Gumerov, A.M.; Deberdeev, R.Y. Immobilization of Organic Reagents on Optically Transparent Mesoporous Polymers and Its Analytical Use. Rus. J. App. Chem. 2015, 3, 495-501. [CrossRef]

49. Davletbaeva, I.M.; Mazil'nikov, A.I.; Zaripov, I.I.; Davletbaev, R.S.; Gumerov, A.M.; Parfenov, V.V. Synthesis of Block Copolymers Based on a Macroinitiator and 2,4-Toluene Diisocyanate. Pol. Sci. Ser. B 2018, 1, 34-40. [CrossRef]

50. Robeson, L.M. The upper bound revisited. J. Membr. Sci. 2008, 320, 390-400. [CrossRef]

(C) 2019 by the authors. Licensee MDPI, Basel, Switzerland. This article is an open access article distributed under the terms and conditions of the Creative Commons Attribution (CC BY) license (http:/ / creativecommons.org/licenses/by/4.0/). 